\title{
Examining pre-service mathematics teachers' reasoning errors, deficiencies and gaps in the proof process
}

\author{
Enes Demir¹, Tuğba Öztürk², and Bülent Güven² \\ ${ }^{1}$ Department of Mathematics Education, Siirt University, Siirt, Turkey \\ 2Department of Mathematics Education, Karadeniz Technical University, Trabzon, Turkey \\ For correspondence: tugbaozturk@ktu.edu.tr
}

\begin{abstract}
Proving is a process that has important roles in terms of learning and teaching in almost all the areas of mathematics. Because the process of proof constructions an extensive process that includes skills as mathematical thinking, reasoning and making connections. Reasoning is one of the most important components of this process. However, most students have difficulty in making a good reasoning and they make various reasoning errors in the process. The purpose of the study is to investigate the reasoning errors that pre-service mathematics teachers exhibit during proof construction. This study was carried out with 80 university students from second, third, fourth and fifth grade levels. An openended exam based on abstract mathematics and algebra was used. To deeply examine reasoning errors in the proving process, clinical interviews were conducted with pre-service teachers. A scale was developed by considering the literature review and the expert opinions; this was used to analyse the data about the reasoning errors. The results illustrate that the reasoning errors mostly do not show differences for all grade levels. However, the percentages of reasoning errors according to the grade levels and to the upper classes these errors show resistance to decrease the deficiencies. It is important to design a learning environment enabling students to experience proof construction in order to reduce or eliminate the reasoning errors.
\end{abstract}

Keywords: Pre-Service Teachers, Proof, Proof Process, Reasoning Errors

\section{Introduction}

Proof has an important place in the historical of humanity. Despite the fact that the term of "Proof" started to play an active role systematically in the area of mathematics since the Ancient Greece, "Proof" actually starts together with the history of the human being. Because of man's nature, he feels the need of seeing the validity of a statement or something like that or the need of clearing the suspicions in his mind. This need leads to seeking convincing answers to the questions of "Why?", "What for?". And finally, this seeking introduced the term "Proof". In this sense, proof is one of the concepts that constitute the fundamentals of the mathematics, and mathematical proof is, undoubtedly, one of the most important elements that characterize mathematics and that distinguish it from the other disciplines. For this reason, most researchers describe the "Proof" as the heart of the mathematics (Anderson, 1996; Hanna, 2000; Herbst \& Brach, 2006; Hoyles, 1997; Rav, 1999). What makes "Proof" gain this qualification is its forming a basis that shows whether a mathematical statement or judgement is valid or invalid (Tall \& Mejia-Ramos, 2006).

\section{Theoretical Background}

A mathematical proof not only shows whether a statement is valid or invalid, also why it is valid (Selden \& Selden, 2007; Yackel \& Hanna, 2003). By stating the role of the proof with the sentence, "If problem solving is the heart of the mathematics, proof is the soul of it", Schoenfeld (2009) emphasized that proof is a factor that gives meaning to mathematics and that reveals the meanings that lie 
beneath mathematics. Because recognizing the relationships of mathematical concepts with each other, mathematical thinking and mathematical concept's gaining of meaning are directly related the concept of proof (Flores, 2002; Martinez \& Superfine, 2012).In this respect, rather than being a basic mathematical operation, proof construction is a process that contains cognitive operations (Selden \& Selden, 2003), and the process of proof construction is a structure that supports the development and variation of mathematical thinking (Baki, 2008).

Proving is a process that has important roles in terms of learning and teaching in almost all the areas of mathematics (Selden \& Selden, 2009). But most students are not successful in this process (Lin, Yang \& Chen, 2004; Sowder \& Harel, 2003; Weber, 2005a). Thus, during the process of proof construction, students from all grades can experience various difficulties. Besides making proofs, they cannot even realize whether their proofs are valid or invalid (Weber, 2001), because the process of proof construction is an extensive process that includes skills like mathematical thinking, reasoning and making connections. In addition to these skills, it includes components like abstraction, mental efforts, anticipation, reasoning have important roles in the process of proof construction. Accordingly, reasoning is one of the most important components of the process of proof construction (Almeida, 2003).

Reasoning is described as the process of inferring from the results, judgements, truths or statements and making sure of them (Altıparmak \& Öziş, 2005, Haynes, 1997). Mathematical reasoning is one of the key elements of mathematics and it underlies the process of proof construction. Reasoning in mathematics is not different from any other reasoning in any other subject (Selden \& Selden, 2003). More complicated and superior arguments are needed only for reasoning. Developing reasoning related with these arguments is based on correct application of mathematics and the individual's proficiency level in mathematics (Selden \& Selden, 2003). As a tool in learning mathematics (Knuth, 2002), proof construction is one of the areas where reasoning is employed frequently. When it is taken into consideration that a mathematical study starts with figuring out mathematical relationships and ends with proof, proving is reasoning which can be considered as mental reasoning whose rules and standards have been determined, whereas figuring out the mathematical relationships is a process that requires creativity, anticipation and experience. That creating proofs is among the aims of mathematics and the importance of developing reasoning for students are emphasized in the NCTM Standards (2000): "Recognizing reasoning and proof as fundamental aspects of mathematics, Making and investigating mathematical conjectures; Developing and evaluating mathematical arguments and proofs; Selecting and using various types of reasoning and methods of proof."However, in reasoning which makes sense to individuals and enables them to proceed step-by-step, individuals will fall into a systematic error(is continuously repeated) rather than a simple error(occurs once), when they are making a mathematical proof. Making systematic errors can be classified as reasoning errors.

Reasoning errors will occur basically due to three main reasons which are epistemological, psychological and pedagogical. Moreover, some of these errors will arise from conceptual errors and some from some teaching techniques that the students experienced before or from any other reason, i.e., cognitive or biological factors (Selden \& Selden, 2003). But the students persist in those kinds of errors because they cannot recognize that they are actually errors. It can be stated that this issue can be experienced by other students who are at a different level of education (Weber, 2001). Some research has indicated that students from different levels of education make reasoning errors (Andrew, 2009; Jones, 2000; Sarı-Uzun, 2013; Selden \& Selden, 2003; Selden \& Selden, 2009; Weber, 2001).

Jones (2000) stated that in understanding and developing the proof during the process of proof construction, students experience difficulties in following the steps of reasoning and converting them into formal ones and make errors like getting contrary results from similar proofs. Selden and Selden 
(2003) also indicated that students make reasoning errors like using the converse of a theorem, errors galore, validity of the apparent differences and the gaps/holes. A scale that was developed in order to evaluate the errors made during proof process by Andrew (2009) included errors like ignoring the definition range in using variables while making a proof, the failure of the predetermined approach during a proof construction process, making a proof by considering a specific situation, making a wrong assumption while starting the proof construction process and not following reasonable steps throughout the proof construction process. Sari-Uzun (2013) pointed out that the difficulties experienced by students during proof construction processes result from errors and deficiencies in mathematical language and notation, incapability in forming proof frame, lack of knowledge about proof methods, focusing on a particular proof method, failure in starting proof or assuming the result. Another result revealed from these studies is that the teachers also have an important effect on the students' reasoning errors. In this respect, developing proof writing skills throughout students' university education is very significant for pre-service teachers. In this paper, the reasoning errors of pre-service mathematics teachers will be discussed in broader perspective and reasoning errors will be classified in different categories. Thus, these errors will be determined more clearly. We hope to help the instructors to realise their students' reasoning errors. This paper may contribute to be designed effective learning environment on proof and form the basis for future research on eliminating the reasoning errors.

\section{The Purpose of the Study}

One of the most important goals of teaching mathematics is to find reasonable answers for the questions of "Why?" and "What for?", in other words to enable reasoning to develop (Altiparmak \& Öziş, 2005). In this regard, recently in our country, mathematics curricula for secondary education have been reorganized in accordance with the recent goals and attainments. The importance of developing problem solving, mathematical thinking, mathematical proof making, mathematical reasoning skills, and being capable of doing abstraction is also emphasized (MEB, 2013).Similarly, all around the world, most of the developed countries include reasoning, proof and proof processes in their mathematics curricula for secondary education and lay stress on its importance. According to research (Ball, Hoyles, Jahnke \& Movshovitz-Hadar, 2002; Selden \& Selden, 2003; Yackel \& Hanna, 2003), proof is one of the most important components of mathematics education. The main purpose of these studies is to give wide insight in reasoning and proof to pre-service mathematics teachers, because ifa teacher has a limited understanding and background related to proof and reasoning, then this may lead the students to make lots of reasoning errors during proof construction or this may lead them to continue with their current errors (Stylianides \& Stylianides, 2009).For teachers to be able to unearth the students' capabilities, firstly they should be well acquainted with that topic (Baki, 1999).Otherwise, it will be hard for them to guide the students during proof construction (Aydoğduİskenderoğlu \& Baki, 2011). If a teacher doesn't know how to reason logically during proof construction or has not developed the required skill for that, it will be very unlikely for him/herto give reliable information about it. Thus, the determination of the reasoning errors, reasoning deficiencies, and reasoning gaps of pre-service teachers and conducting studies for helping students improve their reasoning skills is important. There is a lot of work by psychologists like Lance Rips, etc., on the frequency of reasoning errors in the general population. But there is few studies in mathematics education. The fact that in the literature reasoning errors are named differently by different researchers, and that the researches cannot reach a consensus on error types and the frequency of them shows that it is worth conducting studies on the frequency and the types of those errors. The purpose of the study is to investigate the reasoning errors, the reasoning gaps, and the reasoning deficiencies that pre-service mathematics teachers exhibit during proof construction. In accordance with this purpose, we will try to answer the following questions in this paper.

1. Which reasoning errors do pre-service mathematics teachers make more common in the process of proof construction?

How do these reasoning errors change in different grade levels? 


\section{Method}

In order to identify pre-service mathematics teachers' reasoning errors, deficiencies, and gaps during proof construction, both qualitative and quantitative approaches were used. For this purpose, an open-ended exam based on abstract mathematics and algebra was developed. To deeply examine reasoning errors, deficiencies and gaps in the proving process, clinical interviews were conducted with randomly-selected pre-service teachers. The data were analysed using a scale that was developed by consulting studies in the literature and considering expert opinions to determine reasoning errors, deficiencies and gaps.

\section{Sample}

This study was carried out with second, third, fourth and fifth year university students. Twenty students from each level who have already taken courses as abstract math, algebra, analysis, and fundamentals of mathematics were randomly selected. When selecting the sample group, it is considered that pre-service teachers have had courses in which proving was stressed.

\section{Data Collection Tools}

In the study, an open-ended examination was conducted to determine the pre-service mathematics teachers' reasoning errors, deficiencies, and gaps exhibited during proof construction. In developing this open-ended examination, firstly reasoning errors in the literature were examined; then a question pool was generated by observing the calculus, algebra, abstract math, and general mathematics courses. The researchers participated in courses to observe which theorems were proved in the class and noted them to develop open-ended examination. The questions were finalized taking account of expert opinion. The experts teach courses related with proving. In addition, it was considered that the questions should be related with fundamental mathematical knowledge. The examination continued about 80 minutes and the pre-service teachers were not allowed for using any resources (e.g., their books, notes, the internet). Besides, the clinical interviews were carried out with the pre-service teachers who selected randomly. The questions and the reasoning errors, deficiencies, and gaps that were foreseen for each question are given below in Table 1.

Table 1. The questions and the reasoning errors, deficiencies, gaps for each question

\begin{tabular}{ll}
\hline Questions & The reasoning errors, deficiencies, gaps for each question \\
\hline & - Beginning with the conclusion (RE1) \\
Q1: For any positive integer n, if & - Beginning with incorrect assumption (RE2) \\
$n^{2}$ is a multiple of 3, then $n$ is & - Accepting different notations as a proof (RE3) \\
a multiple of 3. & - Introducing variables without considering the definition \\
& range (RD3) \\
& - The gaps of proof steps and the results (RG1) \\
\hline Q2: For a, b prime numbers & - Accepting a case or specific value as a proof (RE7) \\
and $a>2, b>2$, prove & - Deficiencies of defining the variables or using \\
whether or not $a^{2}-b^{2}$ is & unnecessary variables (RD5) \\
prime. & - Deficiencies of beginning proof process (RD2) \\
\hline Q3: For $\forall x \in R$, prove that & - Beginning with the conclusion (RE1) \\
$x+\frac{1}{x} \geq 2$. & - Using the converse of theorem (RE6) \\
\hline Q4: Prove that $f, g: R \rightarrow R$ & - Deficiencies of using proof methods (RD1) \\
$(f o g)^{-1}=g^{-1} o f f^{-1}$ & - Accepting a case or specific value as a proof (RE7) \\
\hline & - Writing proof by considering only one condition (ME8) \\
\hline & - Accepting different notations as a proof (RE3) \\
Q5: For $a, b \in Z$, if $(a, b)=1$, & - Accepting a case or specific value as a proof (RE7) \\
$a|n, b| n$, prove that $a b \mid n$ & - Introducing variables without considering the definition \\
& range (RD3)
\end{tabular}




\begin{tabular}{cl}
\hline Q6: For $\forall x, y \in \mathrm{R}$, prove that & - Accepting a case or specific value as a proof (RE7) \\
$|x+y| \leq|x|+|y|$ & - Deficiencies of using proof methods (RD1) \\
& - Using inadequate knowledge of mathematical theorems \\
& and concepts (RD4) \\
\hline Q7: For $\forall a, b \in Z$, prove that if & - Beginning with incorrect assumption (RE2) \\
$a+b$ is an odd number, one & - Deficiencies of using proof methods (RD1) \\
of $a$ and $b$ is an odd number & - Deficiencies of using mathematical language (RD6) \\
and other is even number. & - The gaps of proof steps and the results (RG1) \\
\hline Q8: For $m, n \in Z$, show that there & - Accepting different notations as a proof (RE3) \\
is not any solution of & - Accepting a case or specific value as a proof (RE7) \\
$m^{2}+m=2 n+1$. & - Deficiencies of beginning proof process (RD2)
\end{tabular}

\section{Data Analysis}

A scale was developed by considering the literature review and the expert opinions; this was used to analyse the data about the reasoning errors, deficiencies, and gaps that occurred on the open-ended examination and the clinical interviews. Although several reasoning errors were determined by different researchers in the literature (Andrew, 2009; Jones, 2000; Sar1-Uzun, 2013; Selden \& Selden, 2003; Weber, 2001), researchers were in coherence about types of reasoning errors as beginning with the conclusion, beginning with an incorrect assumption, deficiencies of using mathematical language, writing proof without all of main steps etc. In this study, these errors were classified by three categories: reasoning errors, reasoning deficiencies and reasoning gaps. Reasoning errors in the proving process are errors that lead to a systematic error rather than a simple error. It can be stated that these errors are generally starting with incorrect assumptions in the beginning of the proof, putting forward invalid reasoning or not making generalizations using specific values. In other words, proof that includes reasoning errors do not represent valid proof. Reasoning deficiencies are situations resulting from finishing proofs with deficiencies based on proof methods, definition range and mathematical language or from leaving it half finished. Rather than being related with reasoning errors, these situations are related with starting with correct reasoning but not being able to complete a proof in expected ways due to lack of some mathematical knowledge. Reasoning gaps are completing the proof without giving justifications for the operations and the statements used in the proof steps or without setting any relationship between those steps. In determining these categories, the literature was also consulted. In the following categories, the names of some reasoning errors are the same as those in the literature consulted. The rubric for the determination of reasoning errors in the students' work is given below in Table 2 .

Table 2.The rubric for the determination of reasoning errors

\begin{tabular}{|c|c|c|c|c|c|}
\hline \multicolumn{2}{|r|}{ Reasoning Errors } & \multicolumn{2}{|c|}{ Reasoning Deficiencies } & \multicolumn{2}{|r|}{ Reasoning Gaps } \\
\hline RE1 & $\begin{array}{l}\text { Beginning with the } \\
\text { conclusion }\end{array}$ & RD1 & $\begin{array}{l}\text { Deficiencies of using } \\
\text { proof methods }\end{array}$ & RG1 & $\begin{array}{l}\text { The gaps of proof } \\
\text { steps and the results }\end{array}$ \\
\hline RE2 & $\begin{array}{l}\text { Beginning with an } \\
\text { incorrect assumption }\end{array}$ & RD2 & $\begin{array}{l}\text { Deficiencies of } \\
\text { beginning proof } \\
\text { process }\end{array}$ & RG2 & $\begin{array}{l}\text { Using theorems and } \\
\text { concepts without } \\
\text { justifications }\end{array}$ \\
\hline RE3 & $\begin{array}{l}\text { Accepting different } \\
\text { notations as a proof }\end{array}$ & RD3 & $\begin{array}{l}\text { Introducing variables } \\
\text { without considering } \\
\text { the definition range }\end{array}$ & RG3 & $\begin{array}{l}\text { Writing proof } \\
\text { without all of main } \\
\text { steps }\end{array}$ \\
\hline RE4 & $\begin{array}{l}\text { Using several variables } \\
\text { for an expression }\end{array}$ & RD4 & $\begin{array}{l}\text { Using inadequate } \\
\text { knowledge of } \\
\text { mathematical } \\
\text { theorems and } \\
\text { concepts }\end{array}$ & RG4 & $\begin{array}{l}\text { Using extraneous } \\
\text { details or steps }\end{array}$ \\
\hline
\end{tabular}




\begin{tabular}{llll}
\hline RE5 & $\begin{array}{l}\text { Real numbers are } \\
\text { universal }\end{array}$ & RD5 & $\begin{array}{l}\text { Deficiencies of } \\
\text { defining the } \\
\text { variables or using } \\
\text { unnecessary } \\
\text { variables }\end{array}$ \\
\hline RE6 & $\begin{array}{l}\text { Using the converse of } \\
\text { theorem }\end{array}$ & RD6 & $\begin{array}{l}\text { Deficiencies of using } \\
\text { mathematical } \\
\text { language }\end{array}$ \\
\hline RE7 & $\begin{array}{l}\text { Accepting a case or } \\
\text { specific value as a } \\
\text { proof }\end{array}$ & RD7 & $\begin{array}{l}\text { Writing proof } \\
\text { without systematic } \\
\text { steps }\end{array}$ \\
\hline & RD8 & $\begin{array}{l}\text { Writing proof by } \\
\text { considering only one } \\
\text { condition }\end{array}$ \\
\hline
\end{tabular}

\section{Results}

The results of this study carried out for determining the reasoning errors of the pre-service mathematics teachers during proof construction are presented below under the titles of pre-service mathematics teachers' reasoning errors, reasoning deficiencies and reasoning gaps during proof process.

Pre-Service Mathematics Teachers' Reasoning Errors during Proof Construction

The reasoning errors detected in this study are presented with their definitions and examples.

RE1. Beginning with the conclusion: The error is about starting a proof by accepting, beforehand, a mathematical statement which one should get by starting with an existing fact. This situation is about doing a mathematical operation in reverse of a mathematical statement. This is one of the most common reasoning errors in proof construction. Below there is an example of reasoning errors related to beginning with the conclusion in Figure 1

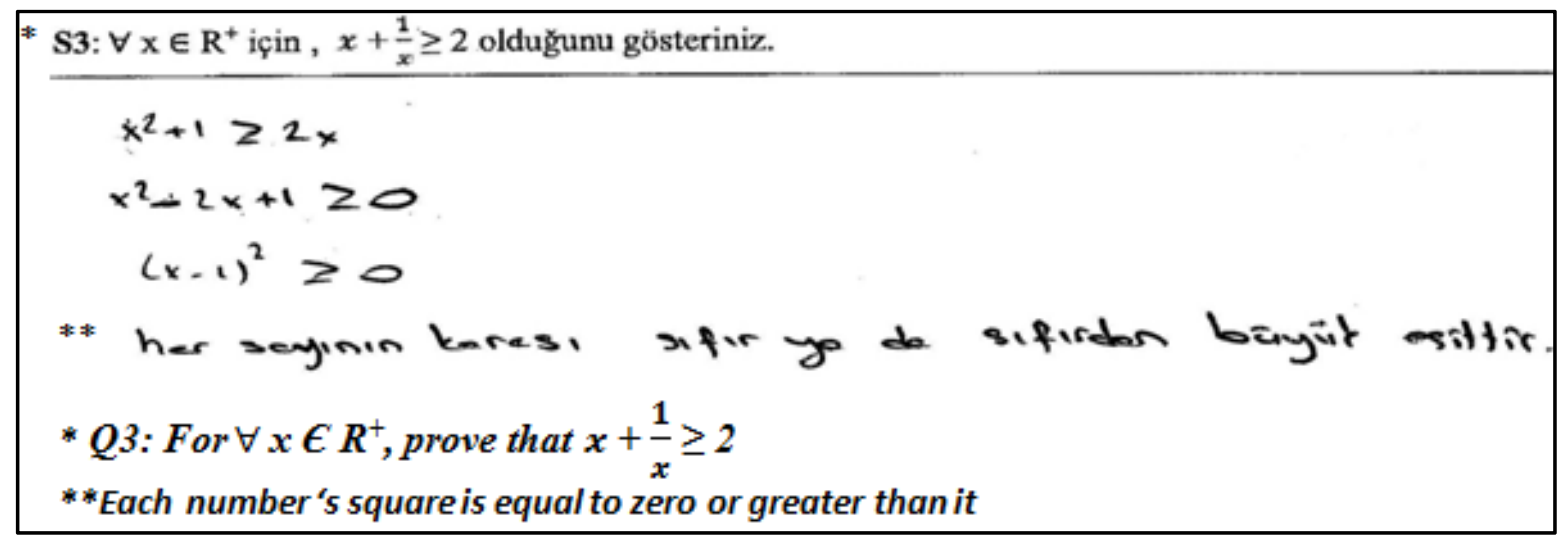

Figure 1.Example of RE1

Above, the pre-service teacher reached the mathematical statement $(x-1)^{2} \geq 0$, whose validity is mathematically very clear, by doing various legitimate operations on the statement which is to be proved. The pre-service teacher, by reaching a valid mathematical statement, argued from the conclusion to a mathematical valid statement and presented these as a proof. Rather than reaching the statement which is expected to be proved, the pre-service teacher considered that he completed the proof by coming up with the true statement of $(x-1)^{2} \geq 0$, which is in fact a consequence of the statement to be proved. 
RE2. Beginning with incorrect assumption: This error is about mixing up the two terms, "hypothesis" and "conclusion", in a mathematical statement to be proved. In other words, the hypothesis is proved by presuming the conclusion is valid. Below, there is an example of reasoning errors related with beginning with an incorrect assumption in Figure 2.

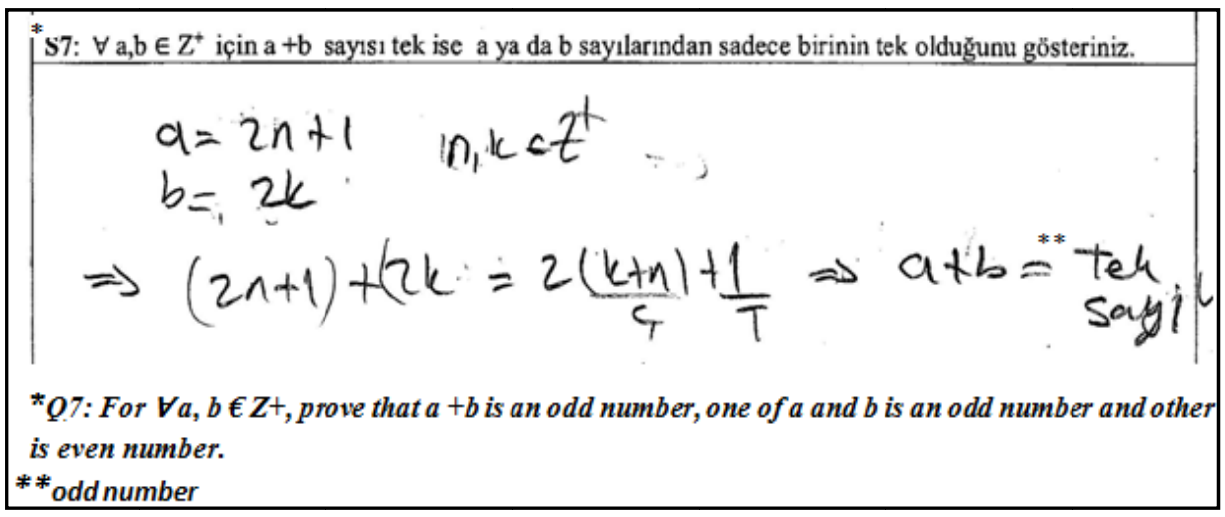

Figure 2. Example of RE2

When the above proof of Q7, done by another pre-service teacher is examined, it can be seen that he mixed the terms of hypothesis and conclusion in the statement to be proved. The actual statement to be proved is that either or is oddprovided is odd. But the pre-service teacher tried to show that the statement of is odd by assuming that is odd and is even. By doing this, the preservice teacher made an effort to prove the information which is given in the hypothesis. Thus, the error was categorized as one of the reasoning errors related to beginning with an incorrect assumption.

RE3. Accepting different notations as a proof: This error is about considering different equations of a mathematical statement as proof. In a sense, it is about accepting different representations of a mathematical statement as proof. Below, there is an example of reasoning errors related to using different notations as proof in Figure 3.

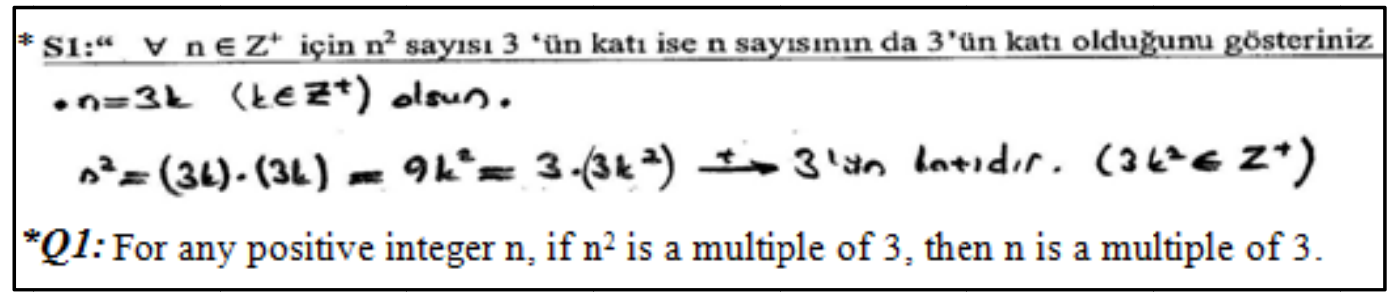

Figure 3. Example of RE3

In this proof attempt, it is can be seen that this pre-service teacher considered several different versions of the original mathematical statement as a proof. In this proof attempt, the pre-service teacher defined the positive number " " as . After squaring both sides of the equation, he accepted that is the multiple of and thought that in this way he/she had managed to show that is the multiple of . Although the operations done by the pre-service teacher are mathematically correct, they do not make any sense for the situation expected to be proved, because he/she did nothing more than write different equivalent equations for the hypothesis. This error is considered to be one of the reasoning errors that are related to using different notations as proof.

RE4. Using several variables for an expression: This error is about the defining of a statement with more than one variable. Below, there is an example of reasoning errors related to using several variables for an expression in Figure 4. 


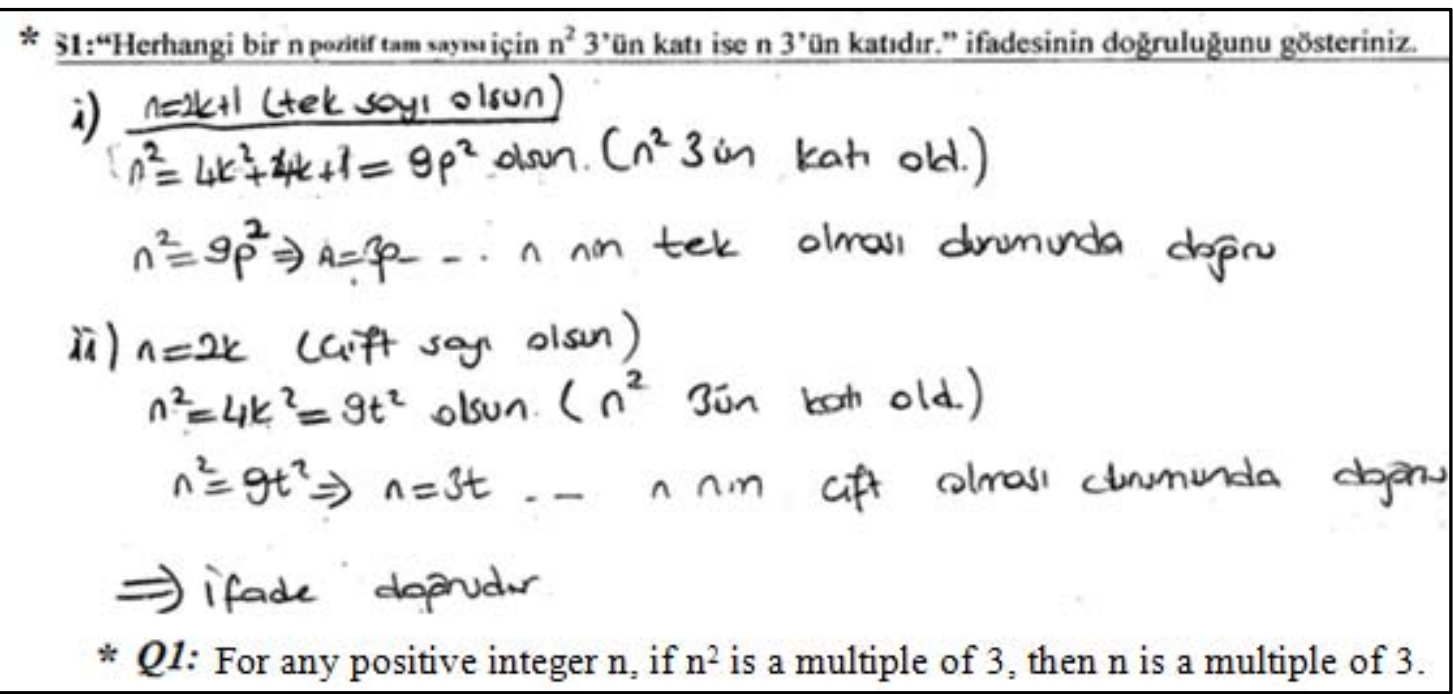

Figure 4. Example of RE4

When the operations in the above proof attempt of Q1are examined, it is seen that the pre-service teacher defined more than one variable like $k$ and $p$ for the same mathematical statement during the steps he followed while defining variables in doing the proof of the mathematical statement. This definition for mathematical statements can lead to complexity during proof construction. Thus, the pre-service teacher made a reasoning error by using more than one variable for the same statement in the proof of the mathematical statement.

RE5. Real numbers are universal: This error is about sticking to the definitions excessively and considering that a rule that is valid for real numbers or whole numbers is also valid for the all sets of the numbers. Below, there is an example of reasoning errors related with real numbers are universal in Figure 5.

S7: $\forall \mathrm{a}, \mathrm{b} \in \mathrm{Z}^{+}$için $\mathrm{a}+\mathrm{b}$ sayısı tek ise a ya da b sayılarından sadece birinin tek olduğunu gösteriniz. ${ }^{*}$

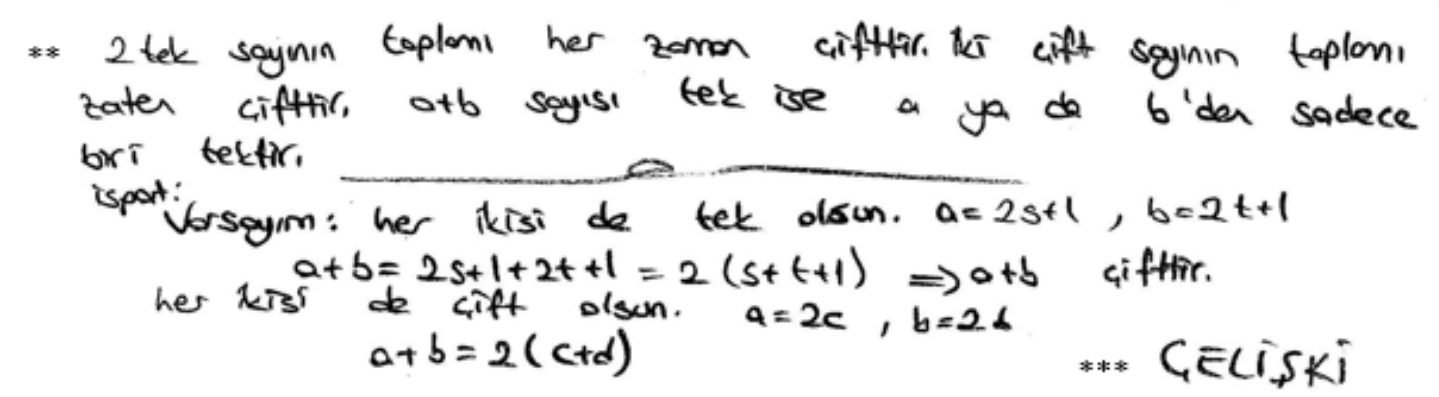

* $Q 7:$ For $\forall a, b € Z+$, prove that $a+b$ is an odd number, one of $a$ and $b$ is an odd number and other is even number.

** The sum of two odd number is always even, and the sum of the two even number is always even. if $a+b$ is odd number $a$ or $b$ is odd number.

*** Contradiction

Figure 5.Example of RE5

In examining the above proof attempt, it can be seen that in proving the mathematical statement he excessively stuck to a rule which is valid for real numbers. In this question, the pre-service teacher stated directly that the sum of two odd numbers is always even and defined the numbers of $a$ and $b$ as odd numbers and as $a=2 s+1$ and $b=2 t+1$ without stating the domain of the variables of $s$ and $t$. He did not define the domain of the $s$ and $t$ variables. In this way, he ignored the fact that $a$ 
and $b$ are not always odd numbers. For instance, when $s$ is defined as $1 / 2(s=1 / 2), b$ is an even number. Without recognizing that, the pre-service teacher tried to complete the proof through depending on the validity of just on rule or considering the rule as universal. Therefore, the reasoning error made by him is determined to be one of the reasoning errors related with Real numbers are universal.

RE6. Using the converse of theorem: This error is about the usage of the converse of a theorem, which is its logical equivalent, in situations where it is difficult to prove the theorem directly. Although this method can be preferred for proof of some theorems, it is generally mixed with the contradiction method. Below there is an example of using the converse of theorem incorrectly in Figure 6.

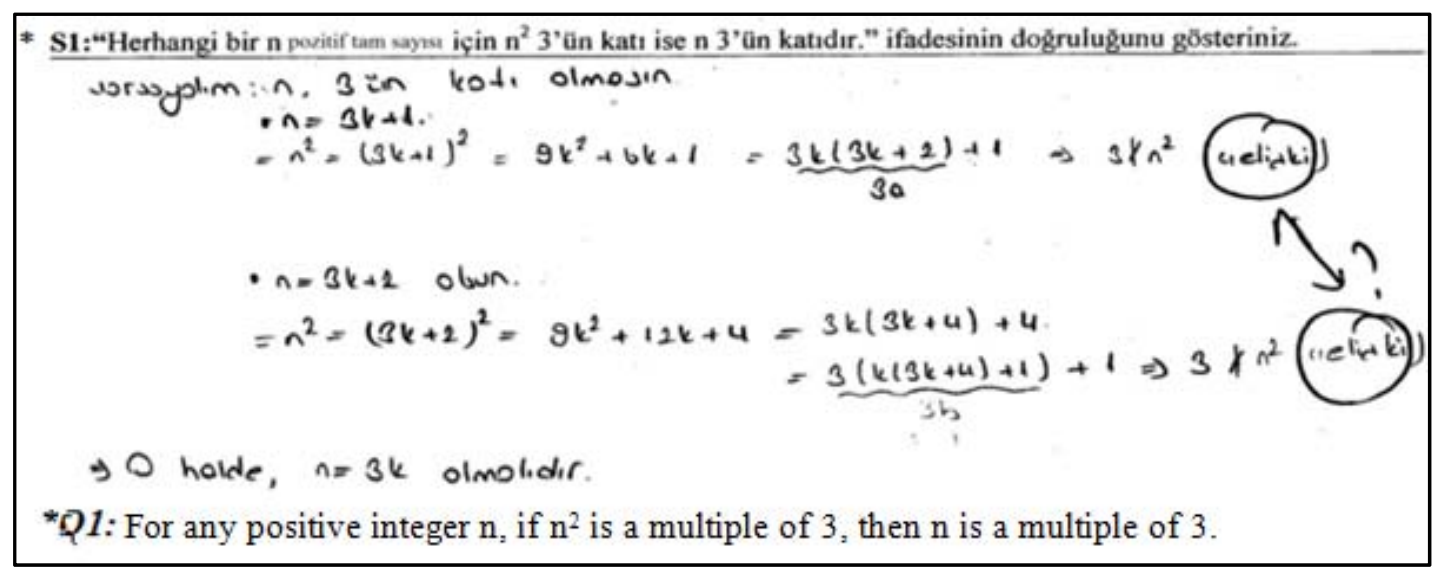

Figure 6. Example of RE6

When this proof attempt of Q1, it can be seen that the pre-service teacher did not comprehend correctly the proof methods used for proving a mathematical statement and that he confuses the methods. Using the converse of a theorem, which is its logical equivalent, in situations where it is difficult to prove the theorem directly may be used. While trying to use a method like that, the preservice teacher used contradiction method which is another proof method and thus interpreted the result gotten wrongly. This reasoning error he did was defined as not recognizing that using the converse of theorem.

RE7. Accepting an example as a proof: This error is about making proof by just using a specific situation and a few numerical values.Below, there is an example of accepting an example as a proof in Figure 7.

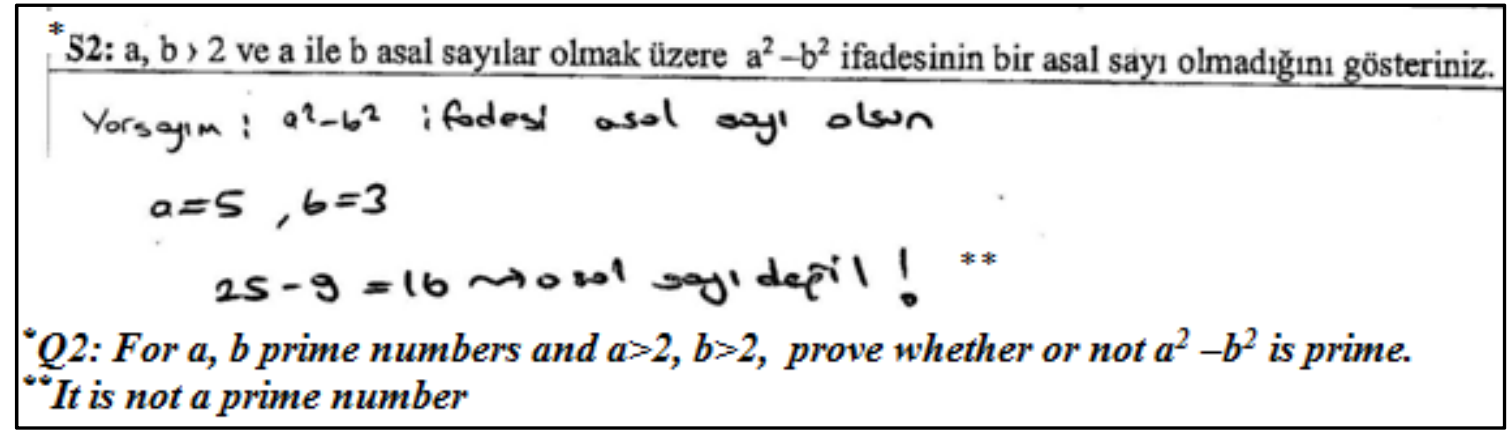

Figure 7. Example of RE7

When this response to Q2 is examined, it can be seen that this pre-service teacher thought that the proof of the correctness of a given mathematical statement can be dealt with a specific situation or with trying a few numerical values. Interviews conducted with the pre-service teacher supported his thoughts. By trying the numerical values of " $a=5$ " and " $b=3$ ", the pre-service teacher thought 
that he finalised proof process. With dependence on just that specific situation, his assumption that for every prime number greater than two, this mathematical statement can be obtained shows that he made a reasoning error related with considering accepting a case or specific value as a proof.

Pre-Service Mathematics Teachers' Reasoning Deficiencies during Proof Process

The reasoning deficiencies determined in this study are presented with their definitions and examples.

RD1. Deficiencies of using proof methods: This deficiency is about choosing a proof method which is not appropriate for a proof and not going forward through the steps of the proof and being unsuccessful in making a proof because of that. Below, there is an example of reasoning deficiencies related to deficiencies of using proof methods in Figure 8.

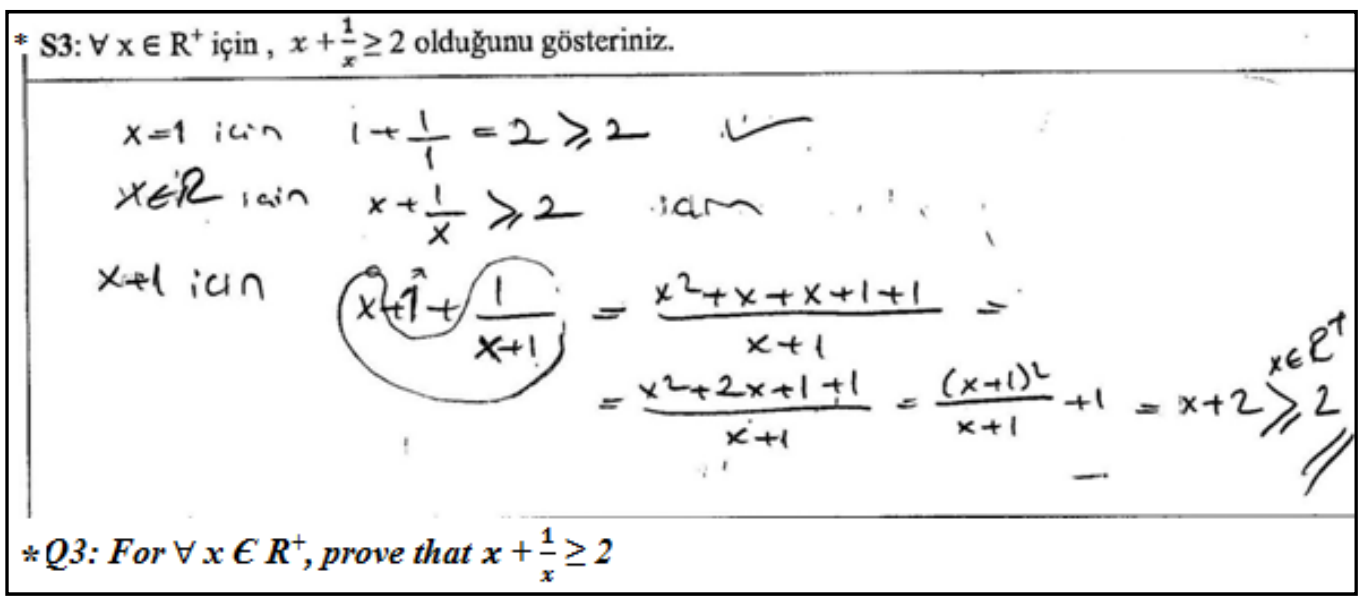

Figure 8. Example of RD1

When the operations done by the pre-service teacher in Q3are examined, it can be seen that the proof method the pre-service teacher usedfor making the proof of the mathematical statement is not appropriate for this question. The steps followed throughout the process are mathematically valid but that method is only appropriate for positive integers. Without recognizing that, the pre-service teacher employed a proof method which is not appropriate for this question. It was concluded that this pre-service teacher did not use an appropriate proof method and so has deficiencies of using proof methods.

RD2. Deficiencies of beginning proof process: This deficiency is about not being able to start a proof or not being able to keep an already started one going despite the fact that there may be a sufficient mathematical background. Below there is an example of reasoning deficiencies related to deficiencies of beginning proof process in Figure 9.

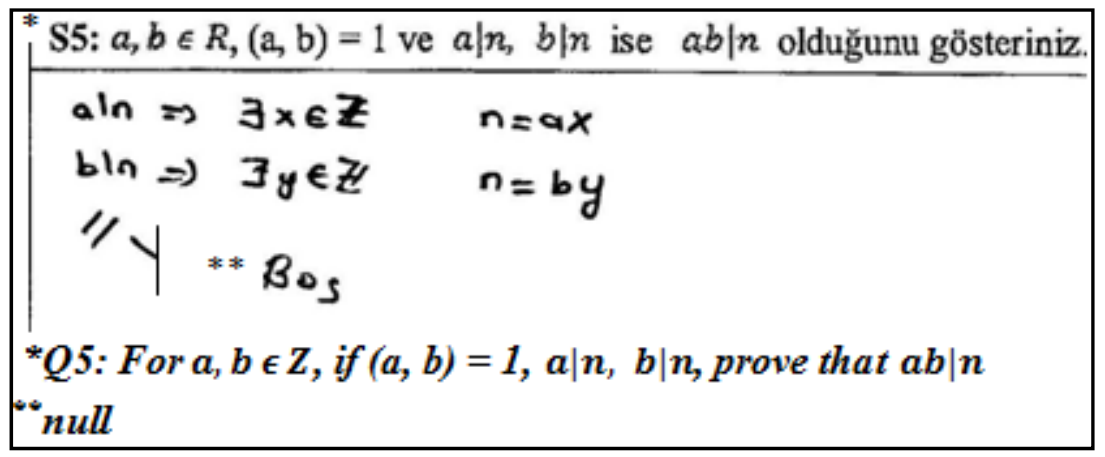

Figure 9. Example of RD2 
When the operations done by the pre-service teacher on Q5are examined, it can be seen that he/she properly defined the given values for making the proof of the mathematical statement. However, he did not continue with the proof although he started the proof by defining the statements of $a \mid$ nand $b \mid$ nas $\exists x \in Z, n=a . x$ and $\exists y \in Z, n=b . y$. In the clinical interviews conducted with the preservice teacher, he stated that initially he thought about some methods for making a proof, but he didn't continue with the proof because he couldn't state those methods mathematically and couldn't decide which method to use. He also stated that with this kind of questions he sometimes follows a way which depends on memorization and consequently he tries hard to remember and mostly he cannot remember. The pre-service teacher left the proof half-finished although hemay have had certain mathematical background. This situation indicates that he has a reasoning deficiency related with deficiencies of beginning proof process.

RD3. Introducing variables without considering the definition range: This deficiency is about using values inappropriate for the statement while making the proof of a mathematical statement or going beyond the definition range. Following there is an example of reasoning deficiencies related with introducing variables without considering the definition range in Figure 10.

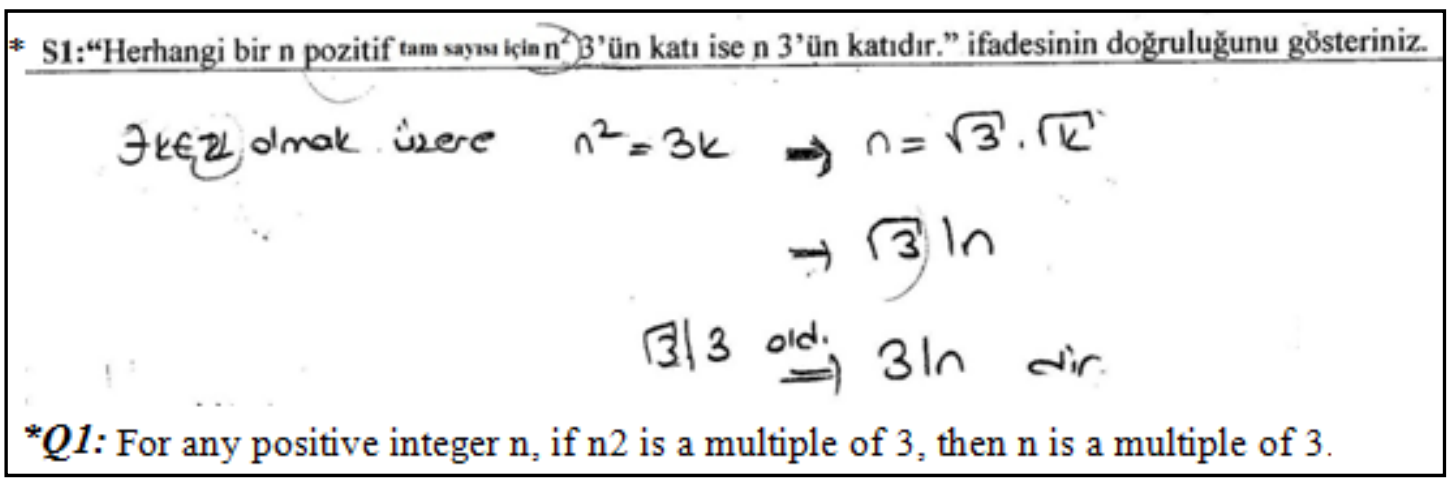

Figure 10. Example of RD3

In making the proof of Q1, the pre-service teacher didn't take the definition range determined for that statement into consideration. Although he was supposed to show $n$ variable for any positive integers, he demonstrated it for all the integers by defining it as $k \in Z$ through going beyond the definition range. Moreover, he considered the variable of $n$ as an irrational number in the other operations he did.

RD4.Using inadequate knowledge of mathematical theorems and concepts: This deficiency is about the usage of mathematical terms or definitions in different meanings and the deficient use of them. Below, there is an example of reasoning errors related to using inadequate knowledge of mathematical theorems and concepts in Figure 11.

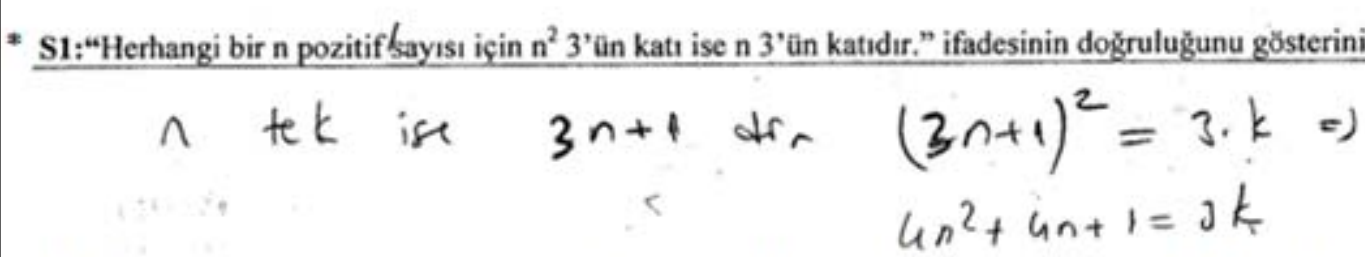

Q $Q$ : For any positive integer $n$, if $n^{2}$ is a multiple of 3 , then $n$ is a multiple of 3 .

Figure 11. Example of RD4

When this proof attempt for Q1is examined, it can be seen that the mathematical terms and statements are wrongly defined. In this question, where he is supposed to define an odd number as 
$k \in Z, n=2 k+1$, he wrongly defined it as $3 n+1$ without definingthe definition range of the variable and also without not using another variable in place of the variable $n$. Consequently, it is realized that one of the reasoning deficiencies the pre-service teacher experienced here is about using inadequate knowledge of mathematical theorems and concepts.

RD5. Deficiencies of defining the variables or using unnecessary variables: This deficiency is about more than enough variables defined throughout the steps of the proof or incomplete definition of the variables. There is an example of a reasoning deficiency related with the deficiencies of defining the variables or using unnecessary variables in Figure 12.

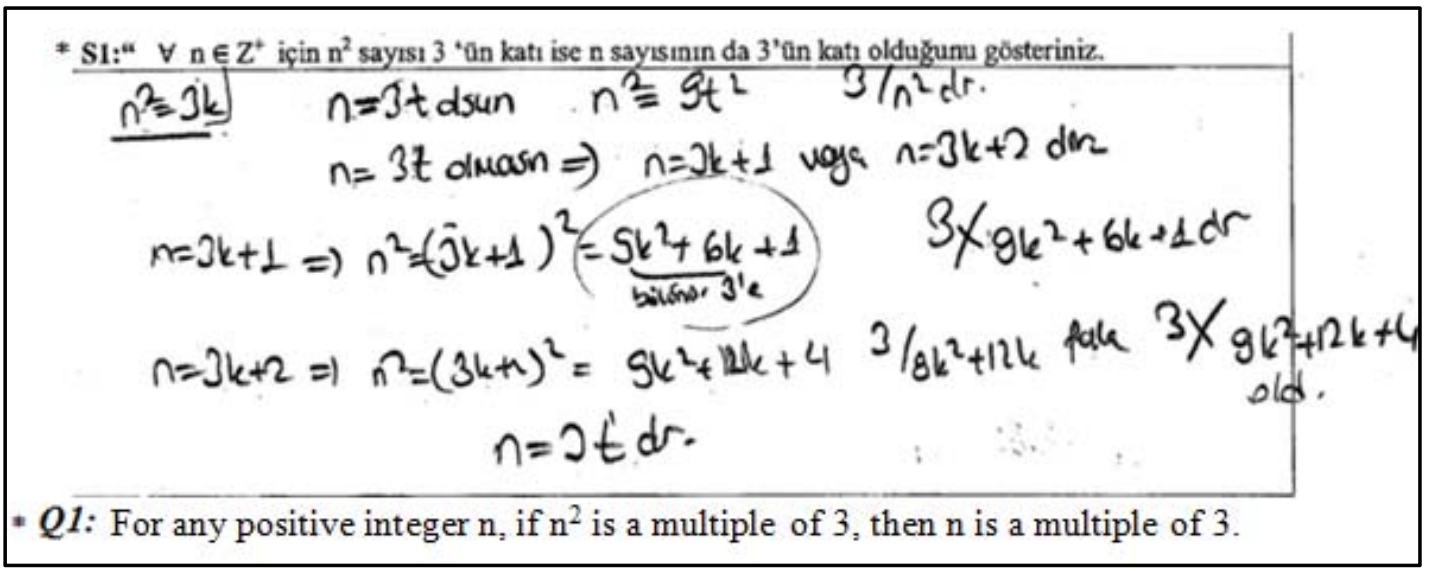

Figure 12. Example of RD5

When this proof attempt is examined, it can be seen that the pre-service teacher used unnecessary variables. He/she continued his proof by defining the variablen as $n=3 k+1, n=3 k+2$ in the other steps of the proof after initially defining it as $n=3 t$. This situation hindered the comprehension of the proof by leading a complication in the steps of the proof. Hence, the reasoning deficiency that the pre-service teacher has here is determined to be related with the deficiency in defining a variable or using an unnecessary variable.

RD6. Deficiencies of using mathematical language: This deficiency is about not being careful with the mathematical language in the usage of statements like mathematical definitions or theorems and mathematical symbols throughout the steps of the proof. Below, there is an example of a reasoning deficiency related to deficiencies of using mathematical language in Figure 13.

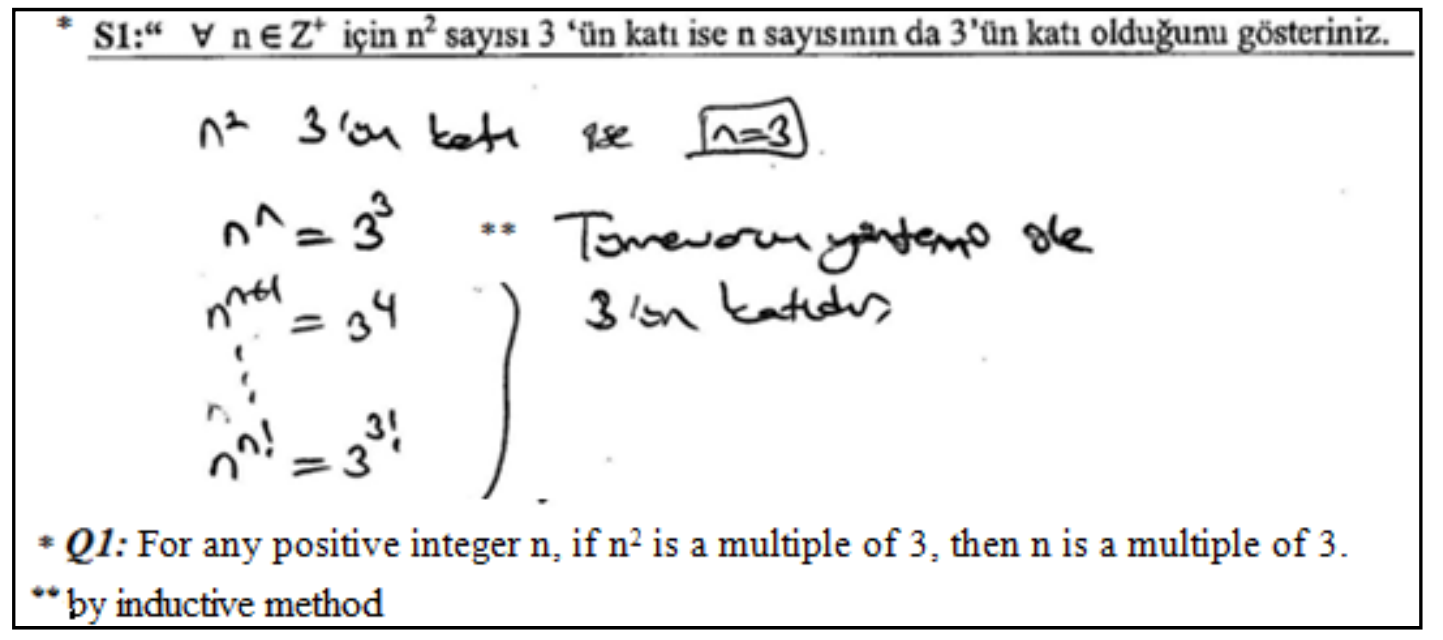

Figure 13.Example of RD6 
When this attempt at a proof for Q1 is examined, one can see that mathematical language was not used properly. The pre-service teacher made definitions like $n^{n}=3^{3}$ orn $n^{n !}=3^{3 !}$ which in fact don't have any mathematical foundation. Depending on the definitions he wrote, he stated that the statement is valid through inductive method. Thus, the pre-service teacher noted some statements that are against the nature of the inductive method. By taking these situations into consideration it is determined that the reasoning deficiency the pre-service teacher experiencing here is related with deficiency in using mathematical language.

RD7. Writing proof without systematic steps: This deficiency is about not following a proper sequence throughout the steps of proof or not writing it in a certain order. Below, there is an example of reasoning deficiencies related with writing proof without systematic steps in Figure 14.

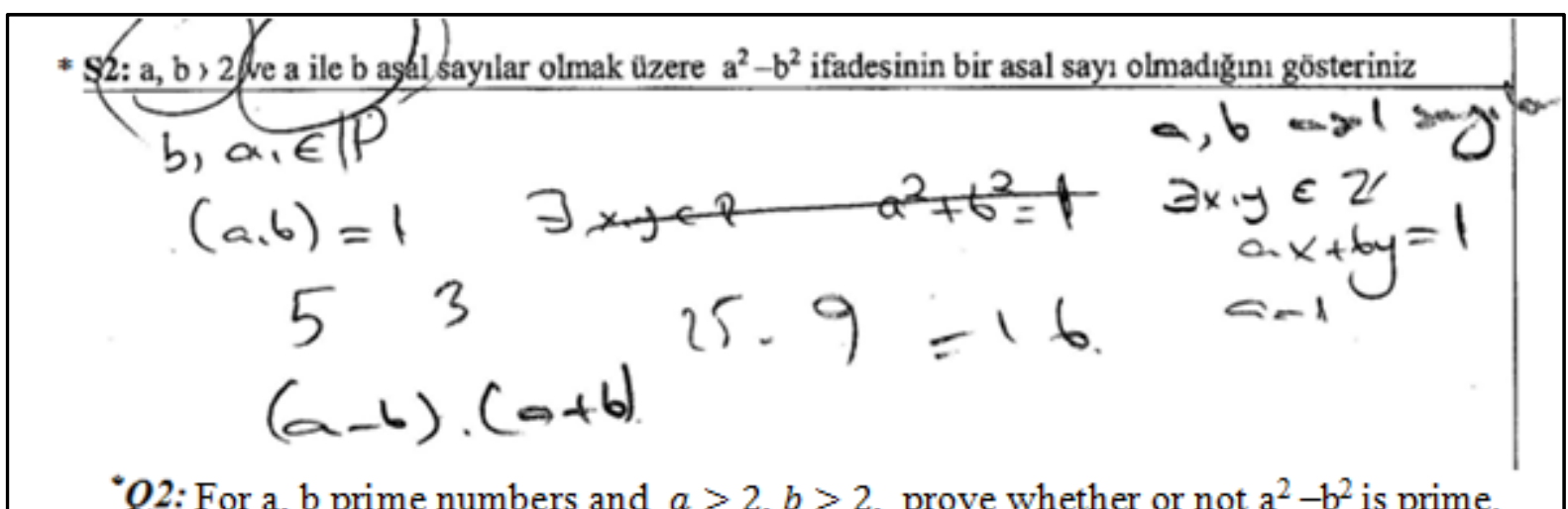

Q 2 2: For a, b prime numbers and $a>2, b>2$, prove whether or not $\mathrm{a}^{2}-\mathrm{b}^{2}$ is prime.

Figure 14. Example of RD7

When the student's work on Q2 is examined, it can be seen that the steps of the proof were not ordered in any reasonable way. The variables $a$ and $b$ were not defined, nor can it be determined which steps were followed afterwards and for what purpose the numerical values were used. This situation led the incomprehensibility of the steps in the proof and their purpose. Therefore, the reasoning deficiency that the pre-service teacher is experiencing here is determined to be related to writing proof without systematic steps.

RD8. Writing proof by considering only one condition: This deficiency is about only proving one implication of a biconditional statement. Below, there is an example of reasoning errors related to writing a proof by considering only one of the two implications in Figure 15.

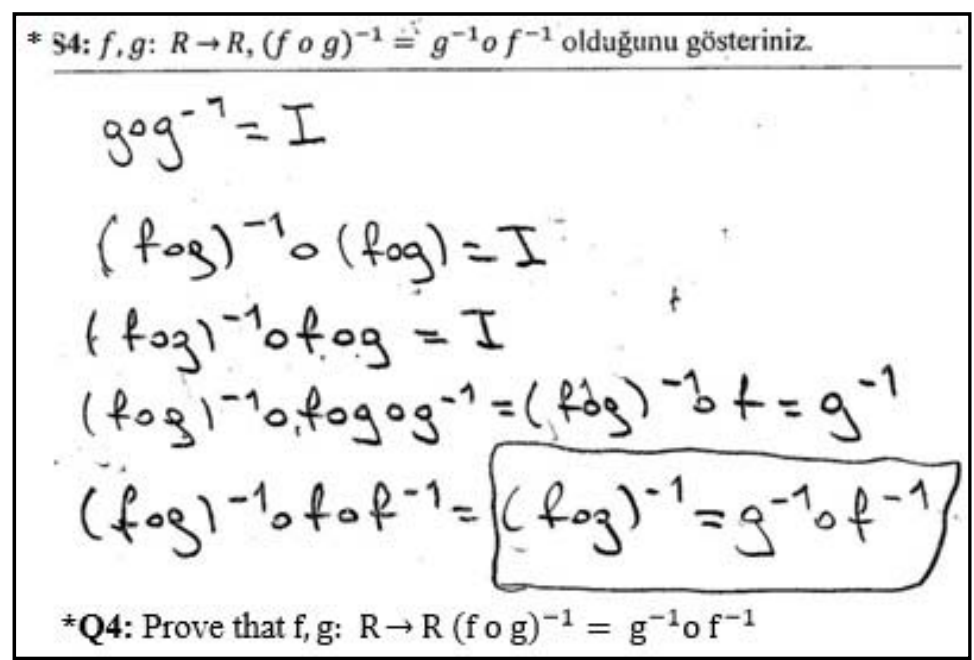

Figure 15. Example of RD8 
When this proof attempt is examined, it can be seen that the pre-service teacher only proved one way of the two-way conditional statement. He ignored the fact that he should also show $g^{-1} \circ f^{-1}(x) o(f \circ g)^{-1}(x)=I(x)$ after $\quad$ showing $(f \circ g)^{-1}(x) \circ g^{-1} \circ f^{-1}(x)=I(x)$. It $\quad$ was decided that he had a reasoning deficiency related to writing proof by considering only one condition.

Pre-Service Mathematics Teachers' Reasoning Gaps during Proof Construction

The reasoning gaps detected in this study are presented with their definitions and examples.

RG1. The gaps of proof steps and the results: This reasoning gap is about the lack of relationship between the steps of a proof despite the fact that the results obtained are based upon the previous steps while the proof of a mathematical statement is made. Following there is an example of reasoning gaps related with the gaps of proof steps and the results in Figure 16.

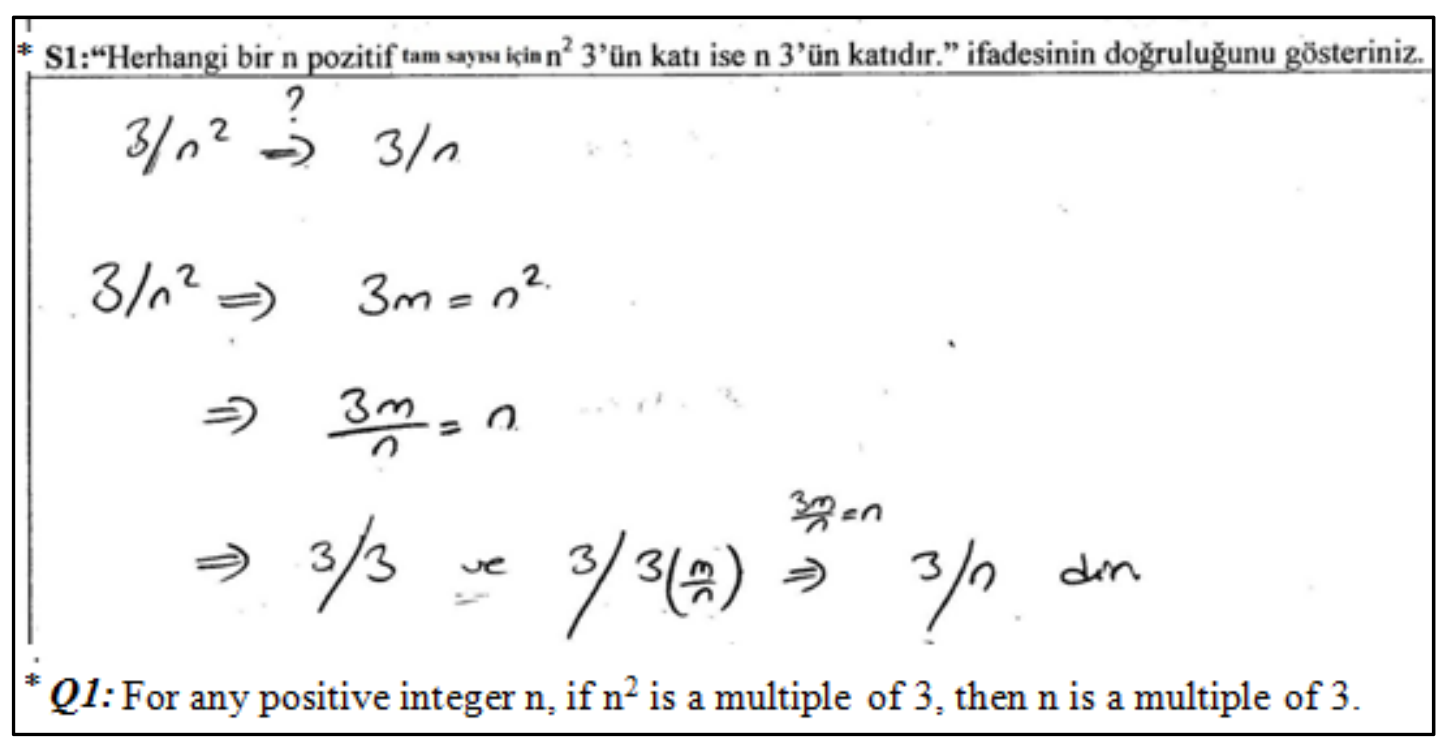

Figure 16. Example of RG1

When this proof attempt of Q1 is examined, it can be seen that there isn't any correspondence among the written proof steps and that the proof steps don't match up with the obtained results. While starting the first step with writing $3 \mid n^{2} \rightarrow 3 m=n^{2}$ the pre-service teacher wrote a result as $3 \mid 3$ and $3 \mid 3\left(\frac{m}{n}\right)$ which is unconnected from the previous steps with the last step of the proof. Consequently, the reasoning gap here is considered to be related to a contradiction between the written proof steps and the obtained results.

RG2. Using theorems and concepts without justifications: This gap is about not giving justifications for the statements used in the proof steps and for the claims presented. Following there is an example of reasoning gaps related with using theorems and concepts without justifications in Figure 17. 


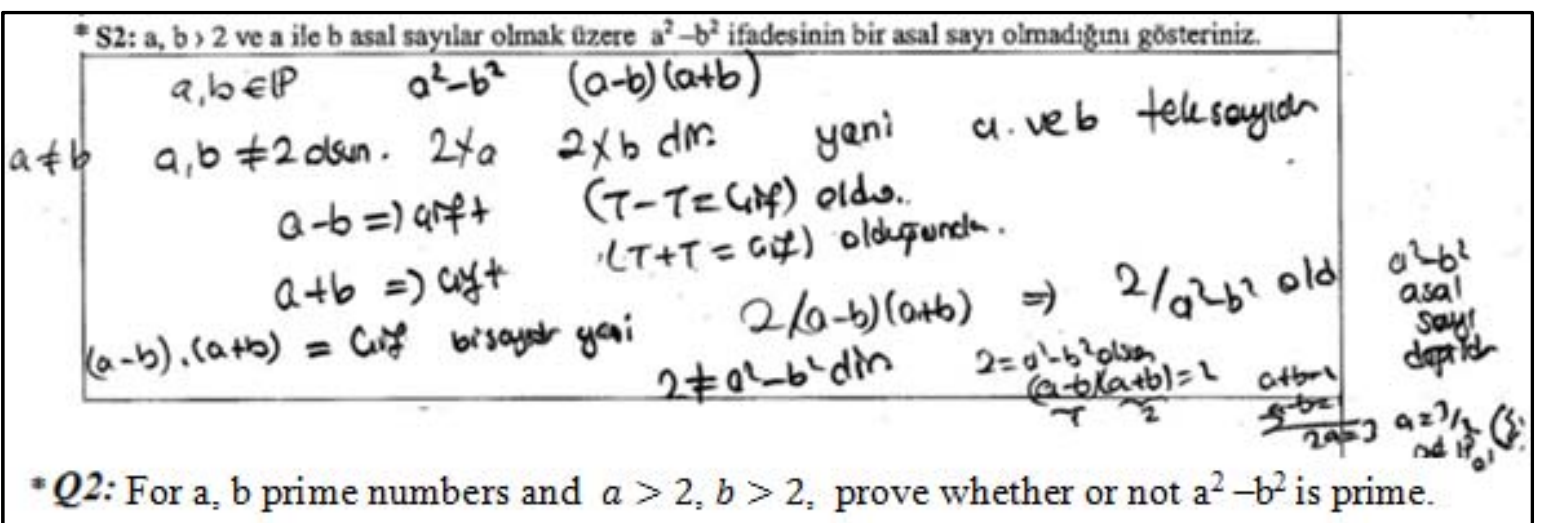

Figure 17. Example of RG2

When this proof attempt of Q2is examined, it can be seen that the pre-service teacher wrote the proof steps by depending upon some propositions without giving any justification for the statements he used throughout the proof process. Without showing that the addition and subtraction of two odd numbers is even, he reached the result by assuming the statements as even. The reasoning gap here is determined to be related to using theorems and concepts without justifications.

RG3. Writing proof without all of the main steps: This gap is about ignoring the steps which are supposed to be written or writing the result without any explanation. Following there is an example of reasoning gaps related with writing proof without all of main steps in Figure 18.

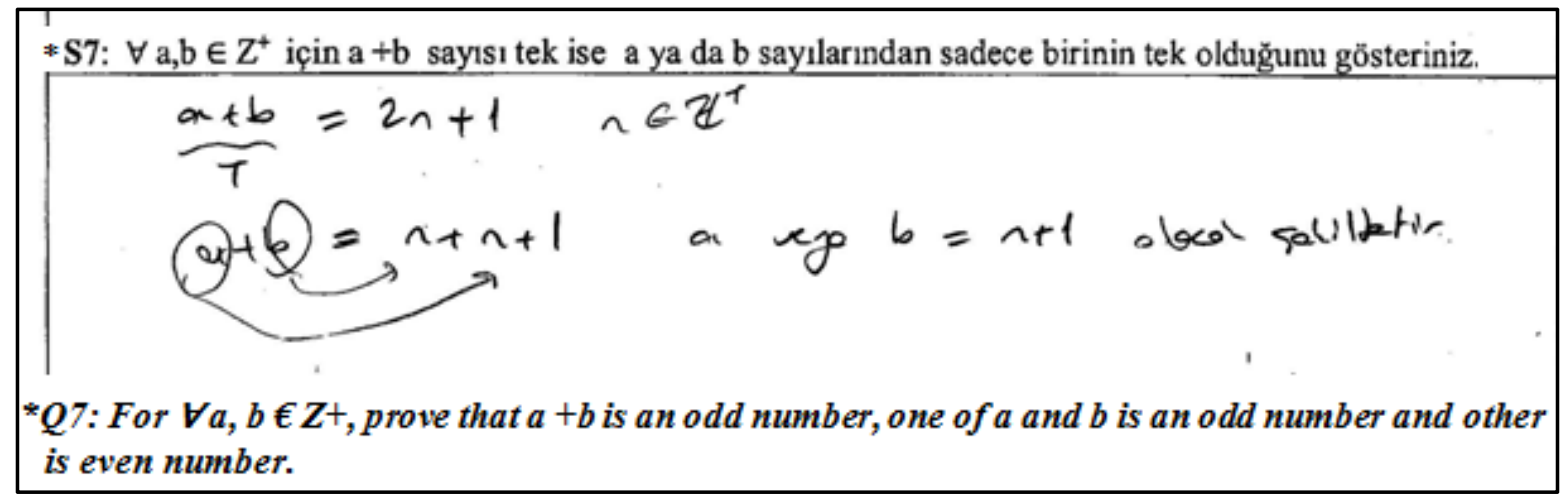

Figure 18. Example of RG3

When this proof attempt of Q7is examined, it can be seen that the pre-service teacher directly wrote the result without including the intermediate steps which are supposed to be written. The pre-service teacher stated that $a$ or $b$ might be the variables $n$ or $n+1$ by defining $a+b$ as an odd number. However, he did not give any details about how he decided this and which steps he followed while deciding. A proof was carried out through ignoring the initial and the last steps of the proof. Thus, the reasoning gap here is defined as writing a proof without all of main steps.

The Comparison of Pre-Service Mathematics Teachers' Reasoning Errors, Deficiencies and Gaps during Proof Construction at Different Grade Levels 


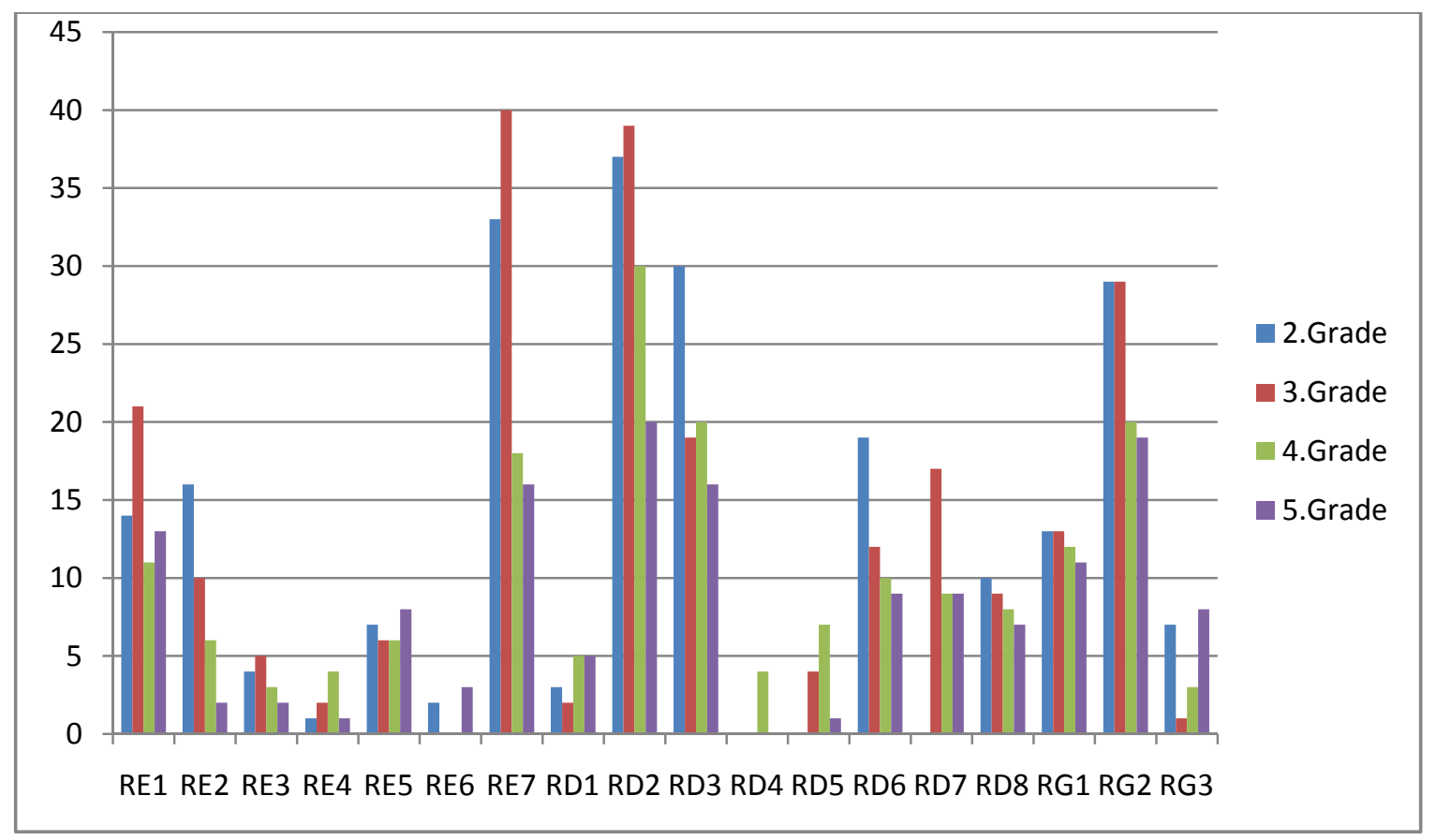

Graph 1. The comparison of reasoning errors, deficiencies and gaps for all grade levels

This graph shows that similar reasoning errors, deficiencies and gaps were determined across all the grade levels in pre-service teachers' proof construction. However, the rates of reasoning errors in the lower grade levels are more than other grade levels. This rate decreases towards the upper grade levels. For example, in third grade level some reasoning errors were determined as 20\% for RE1, 40\% for RE7, 38\% forRD2 and 27\%for RG2, whereas in fifth grade level these errors were determined as $12 \%$ for RE1,20\% for RE7,16\% for RD2, 18\%for RG2. Similarly, other reasoning errors, deficiencies or gaps decrease towards the upper grades.

\section{Conclusion and Discussion}

In this study, the reasoning errors of the different grade levels of pre-service mathematics teachers in the proof construction process were classified; similar reasoning errors, deficiencies and gaps were categorized across all the grade levels. The most frequently encountered errors in the proof process were identified as beginning with the conclusion, accepting a case or specific value as a proof, and beginning with an incorrect assumption. Although other studies have identified similar reasoning errors, they did not provide any results on the frequency of the various categories of reasoning errors (Andrew, 2009; Selden, Mckee \& Selden, 2009; Selden \& Selden, 2003).

In the literature, some studies considered reasoning deficiencies and reasoning gaps under the single category of reasoning errors (Jones, 2000; Sar1-Uzun, 2013; Selden \& Selden, 2003). They did not describe reasoning deficiencies and gaps as different categories. However; in this study, reasoning deficiencies and gaps are divided into sub-components; they are classified into different categories as the reasoning gaps and deficiencies have different meaning from reasoning errors. In this study, the following reasoning deficiencies were determined as the ones occurring most frequently: introducing variables without considering the definition range, deficiencies of beginning proof process and deficiencies of using mathematical language. The emergence of these reasoning deficiencies can be caused of the ignorance of definition range, inappropriate usage of the mathematic language, not highlighting the usage of reasoning methods or excluding students in the proof construction process. Birinci (2010) stated that students assume a passive role trying to remember some reasoning methods learned in courses and as a result of this they break from the proof construction process. Therefore, it must be emphasized to pre-service teachers how and why to use different methods of proof. 
Moreover, the relationships between concepts should be made based on the definition of mathematical concepts and the language of mathematics should be used in the proof construction process. Among the reasoning gaps of the pre-service mathematics teachers in the proof construction process, the following occurred most frequently: Using theorems and concepts without justifications and the gaps of proof steps and the results. The emergence of the reasoning gaps in the proof process may stem from the lack of enough emphasis on the proving steps that follow each other and not expressing definition, theorems and propositions used in proof process when instructors teach proof in their courses. Weber (2005b) also supports this situation stating that instructors' evaluation of the proof steps used to prove a mathematical definition as just only true-false questions and not considering the steps causes students to have the same reasoning errors.

It was determined that the reasoning errors, deficiencies and gaps mostly do not show differences for all grade levels. However, the percentages of reasoning errors, deficiencies and gaps according to the grade levels and to the upper classes these errors show resistance to decrease the deficiencies. This shows that the education they received at university does not make an impact for the reduction or elimination of the reasoning errors. Selden and Selden (2007) support this case stating that traditional approach at the undergraduate education as definition, theorem and proof and failure of the preservice teachers because of the various reasoning errors depending on lecturing of the instructors cause to the failure. In addition, other studies emphasize that students have difficulties in the proof process and fall into a similar reasoning error if these traditional approaches are applied. (Pedemonte, 2007; Sar1-Uzun, 2013; Weber, 2004). In this respect, it is crucial to design a learning environment enabling students to experience proof construction in order to reduce or eliminate the above kinds of reasoning errors.

\section{References}

Almeida, D. (2003). Engenderingproofattitudes: Can thegenesis of mathematicalknowledgeteach us anything?International Journal of Mathematical Education in ScienceandTechnology, 34(4), 479-488.

Altıparmak, K., \&Öziş, T. (2005). Matematiksel ispat ve matematiksel muhakemenin gelişimi üzerine bir inceleme [An investigationuponmathematicalproofanddevelopment of mathematicalreasoning]. Ege Eğitim Dergisi, 6(21), 25-7.

Anderson, J. (1996). The place of proof in school mathematics. Mathematics Teaching, 155, 33-39.

Andrew, L. (2009). Creating a prooferrorevaluationtoolforuse in thegrading of student-generated "Proofs". PRIMUS: Problems, Resources, andIssues in MathematicsUndergraduateStudies, 19(5), 447-462. doi: 10.1080/10511970701765070

Aydoğdu-İskenderoğlu, T., \& Baki, A. (2011). Quantitativeanalysis of pre-service elementarymathematicsteachers' opinionsaboutdoingmathematicalproof. EducationalSciences: TheoryandPractice, 11(4), 2285-2290.

Baki, A. (2008). Kuramdan uygulamaya matematik eğitimi[From theory to practice on mathematics education].Ankara, Turkey: Harf Eğitim Publishing.

Baki, A. (1999). Öğretmen eğitimi üzerine düşünceler [Thoughts on teacher education]. Türk Yurdu, 19(138), 4-9.

Ball, D. L., Hoyles, C., Jahnke, H. N., \&Movshovitz-Hadar, N. (2002). Theteaching of proof. In L.I. Tatsien (Ed.), Proceedings of the International Congress of Mathematicians(Vol. III, pp. 907-920). Beijing, China: HigherEducationPress.

Birinci, K. S. (2010). Matematik öğretmen adaylarının ispatlama performanslarının süreç-nesne ilişkisi açısından incelenmesi [Investigation of mathematics teacher candidates' proof processes in terms of process-object relationship](Master'sthesis). Marmara University, Istanbul, Turkey.

Flores, A. (2002). How do childrenknowthatwhattheylearn in mathematics is true?TeachingChildrenMathematics, 8(5), $269-274$.

Hanna, G. (2000). Proof, explanationandexploration: An overview. EducationalStudies in Mathematics, 44, 5-23.

Haynes, F. (1997). Teachingtothink. AustralianJournal of TeacherEducation, 22(1), 1 - 23.

Herbst, P., \& Brach, C. (2006). Proving and doing proofs in high school geometry classes: What is it that is going on for students? Cognition and Instruction, 24(1), 73-122.

Hoyles, C. (1997). The curricular shaping of students' approaches to proof. For the Learning of Mathematics, 17(1), 7- 16.

Jones, K. (2000). Thestudentexperience of mathematicalproof at universitylevel. International Journal of Mathematical Education in ScienceandTechnology, 31(1), 53-60.

Knuth, E. J. (2002). Proof as a tool for learning mathematics. Mathematics Teacher, 95(7), 486-490.

Lin, F. L., Yang, K. L., \&Chen, C. Y. (2004). Thefeaturesandrelationships of reasoning, proving, andunderstandingproof in numberpatterns. International Journal of ScienceandMathematicsEducation, 2, 227-256.

Martinez, M. V., \&Superfine, A. C. (2012).Integratingalgebraandproof in highschool: Students' workwithmultiplevariablesand a singleparameter in a proofcontext.Mathematical Thinkingand Learning, 14(2), 120-148. doi: 10.1080/10986065.2012.657956

Milli Eğitim Bakanlığı [MEB]. (2013). Ortaöğretim matematik dersi (9, 10, 11 ve 12. simıflar) öğretim programı [Curriculum for secondary school mathematics $\left(9^{\text {th }}, 10^{\text {th }}, 11^{\text {th }}\right.$ and $12^{\text {th }}$ grades]. Ankara, Turkey: Milli Eğitim Press. 
NationalCouncil of Teachers of Mathematics [NCTM]. (2000). Principlesandstandardsforschoolmathematics. Reston, VA: Author. Pedemonte, B. (2007). How can therelationshipbetweenargumentationandproof be analysed? EducationalStudies in Mathematics, $66,23-41$.

Rav, Y. (1999). Why do we prove theorems?Philosophia Mathematica, 7(1), 5-41.

Sarı-Uzun, M. (2013). Matematik öğretmen adaylarının kanıtlama becerilerini geliştirmeye yönelik bir öğretme deneyi [A teachingexperiment on development of pre-service mathematicsteachers' provingskills]. Eğitim ve Bilim [Education and Science], 38(169), 372-392.

Schoenfeld, A. H. (2009). Serieseditor'sforeword. InD. A. Stylianou, M. L. Blanton\& E. J. Knuth (Eds.), Teachingandlearningproofacrossthegrades (pp. xii-xvi). New York, NY: Routledge.

Selden, A., \& Selden J. (2007). Overcomingstudents'difficulties in learningtounderstandandconstructproofs(Report No. 2007-1). Cookeville, TN: TennesseTechnologicalUniversity.

Selden, A., \& Selden, J. (2003). Validations of proofsconsidered as texts: Can undergraduatestellwhether an argumentproves a theorem?JournalforResearch in MathematicsEducation, 34(1), 4-36.

Selden, A., McKee, K., \& Selden, J. (2010). Affect, behaviouralschemasandtheprovingprocess. International Journal of Mathematical Education in ScienceandTechnology, 41(2), 199-215.

Selden, J., \& Selden, A. (2009). Teachingprovingbycoordinatingaspects of proofswithstudents'abilities. In D. A. Stylianou, M. L. Blanton\& E. J. Knuth (Eds.), Teachingandlearningproofacrossgrades: A K-16 perspective (pp. 339-354). New York, NY: Routledge.

Sowder, L., \&Harel, G. (2003). Case studies of mathematicsmajors' proofunderstanding, production, andappreciation. CanadianJournal of Science, Mathematics, andTechnologyEducation, 3(2), 251-267.

Stylianides, A. J., \&Stylianides, G. J. (2009). Proofconstructionsandevaluations. EducationalStudies in Mathematics, 72(2), 237-253.

Tall, D., \&Mejia-Ramos, J. P. (2006, October). Thelong-termcognitivedevelopment of differenttypes of reasoningandproof. Paperpresented at Conference on ExplanationandProof in Mathematics: PhilosophicalandEducationalPerspectives, UniversitatDuisburg-Essen.

Weber, K. (2001). Studentdifficulty in constructingproofs: Theneedforstrategicknowledge. EducationalStudies in Mathematics, 48, 101-119.

Weber, K. (2004). Traditionalinstruction in advancedmathematicscourses: A casestudy of oneprofessor'slecturesandproofs in an introductoryrealanalysiscourse. Journal of Mathematical Behavior, 23, 115-133.

Weber, K. (2005a). A proceduralroutetowardunderstandingaspects of proof: Case studiesfromrealanalysis, CanadianJournal of Science, MathematicsandTechnologyEducation, 5(4), 469-483.

Weber, K. (2005b). Problem-solving, proving, andlearning: Therelationshipbetween problemsolvingprocessesandlearningopportunities in theactivity of proofconstruction. Journal of Mathematical Behaviour, 24, 351360.

Yackel, E., \& Hanna, G. (2003). Reasoningandproof. In J. Kilpatrick, W. G. Martin \& D. Schifter (Eds.), A researchcompaniontoPrinciples and Standards for School Mathematics (pp. 227-236).Reston, VA: National Council of Teachers of Mathematics. 